\title{
The development of a cloud-GIS platform for the management and sharing of geographic data during the central Italy seismic sequence.
}

\author{
MAURIZIO PignONE ${ }^{1}$, ROCCO COGLIANO ${ }^{2}$, RAFFAELE MOSCHILLO ${ }^{1}$ \\ ${ }^{1}$ Istituto Nazionale di Geofisica e Vulcanologia, Centro Nazionale Terremoti,Grottaminarda (AV), Italy \\ ${ }^{2}$ Istituto Nazionale di Geofisica e Vulcanologia, Sezione Roma1, Grottaminarda (AV), Italy \\ maurizio.pignone@ingv.it
}

\begin{abstract}
For several years, the Istituto Nazionale di Geofisica e Vulcanologia (INGV, National Institute of Geophysics and Volcanology) uses ArcGIS Online (www.arcgis.com), to share information about the real-time seismicity in Italy with other geographical data, geological and seismological, through the development of different WebGIS applications with various customized functionalities. During the earthquake emergency in Central Italy in August 2016, WebGIS applications have been widely used. They derive from a common platform developed a few months earlier by the LABGIS of INGV-Irpinia. This platform has enabled the management and updating of the seismic data of the sequence in real time and their integration with the leading INGV databases seismological and seismotectonic and those of other Institutes. Moreover, these applications have permission to manage and share information and even data from the activities of the INGV Emergency Groups, such as the location and characteristics of seismic and accelerometric temporary stations installed by the teams of SISMIKO and EMERSITO and the geological observations from the EMERGEO Group.
\end{abstract}

\section{THE CLOUD-GIS}

$\mathrm{T}$ he Cloud-GIS is the combination of running GIS software and services on cloud infrastructure and accessing GIS capabilities using the web. Cloud computing offers an alternative to traditional methods of delivering and consuming GIS software and services to users. Instead of run- ning on their GIS systems and computing operations, with Cloud-GIS, software and services are hosted on the infrastructure made available through the web technologies. The Cloud-GIS could be defined as a new generation of on-demand GIS technology that uses a virtualized platform or an infrastructure in a scalable dynamic environment. 
For some time different Cloud-GIS platforms are available on the web, free and fee: these platforms allow you to create web maps by integrating local spatial datasets with geographic services available, as the base maps or thematic map services.

One of the most popular platforms is Mangomap (https://mangomap.com/) that lets you transform your data into online web mapping solutions without coding, programmers, servers (cloud-based). With Mangomap (free only for 30 days) it is possible to create maps completely customized but does not allow you to load data from online sources (for example Google drive), but only via upload.

Another Web maps publishing service is QGIS Cloud (https://qgiscloud.com/), it is an open source personal spatial data infrastructure (SDI) on the internet which allow to publish QGIS Desktop projects with maps and data. All maps published on the internet are freely accessible by anyone at zero cost and it's possible to limit the access to your maps. QGIS Cloud allows only viewing and not the editing of a web map created by QGIS desktop project and does not allow to load the dynamic layers.

One of the most widely used cloud platforms by GIS users worldwide is ArcGIS Online, developed by ESRI and available on http://www.arcgis.com, is the cloud-based sharing system "ready to use" that allows a user to build a complete GIS, containing maps and applications, with the possibility of access to a large collection of basic geographical data with worldwide coverage (ESRI Basemaps). This Cloud-GIS allows for creating maps and $\mathrm{Web}$ applications and sharing with different types of users by creating public or private working groups. ArcGIS Online allows the management of different types of geographic data and geospatial applications, made available directly from ESRI or from community of ESRI users around the world. It can be defined as a "social network of geographic information".

ArcGIS Online (Figure 1) allows you to manage and import a large quantity and diversity of information with geographic component from desktop GIS (ESRI shapefile), other GIS software, online resources such as the OGC map-services (WMS, WFS), Google Maps and Google Earth formats (KML and KMZ) and even simple text files and tabular data such as CSV and TXT.

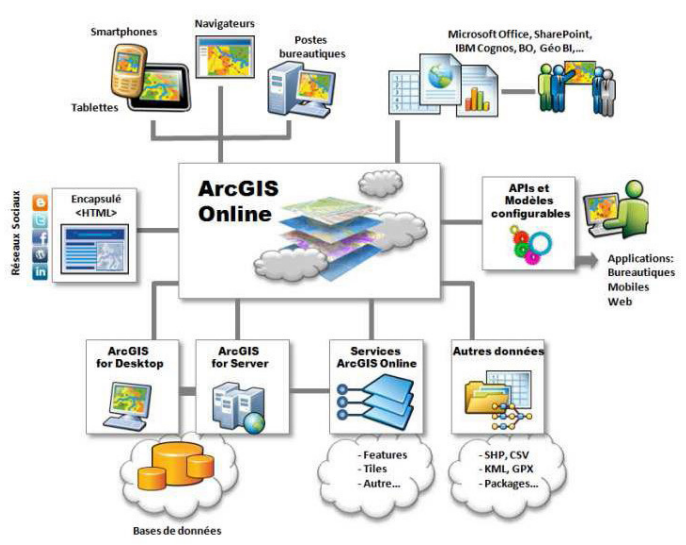

Figure 1: The scheme of ArcGIS Online. It is possible to manage and import a large quantity and diversity of information with geographic components.

With this data it is possible to create, through a very intuitive interface, the Web-maps that represent the starting point for the development of applications WebGIS choosing from the templates available with different features and functionalities. The WebGIS, once created and saved in the Cloud-GIS with its layers and its configurations, can be shared 
with a group of users or shared with everyone and published on the Web.

INGV has its own Cloud space on ArcGIS Online (subscription plan) where it can host web maps, geographic data, Web applications and can be shared within the Institute or outside or with individual working groups. INGV uses ESRI ArcGIS software for creating and managing geographic databases with scientific datasets from its monitoring networks that allow the development of cartographic products and for the web. ArcGIS Online is fully integrated with the other components of the ArcGIS system and this is a huge advantage for the sharing of datasets and creating for web publishing applications. Furthermore, all data uploaded and managed in ArcGIS Online are hosted in "ESRI's Secure Cloud" that ensures their safety and copyright and allowing you to associate to every single dataset, maps or web applications the metadata and a data policy.

\section{THE SEISMIC DATA MANAGEMENT IN REAL TIME}

The real-time seismic data represent a very useful resource especially for emergency management but also for communication and information for the public. The major worldwide centers of seismic monitoring have invested a lot of resources on the sharing of this information in real time through the development of web applications for general users based on digital maps and geographic services. The USGS allows to follow the seismicity around the world through an interactive

map (http://earthquake.usgs.gov/earthquakes/ma $\mathrm{p} /$ ), but also to download different formats data, including geographic (GeoRSS, KML, CSV , Atom, etc.). Similarly, even the CSEM has developed interactive geographical web application to view the real time seismicity in the Mediterranean and around the world (http://www.emsc-

csem.org/Earthquake/significant earthquake s.php). Some of these datasets on seismicity are used in several web portals and smartphones and tablets applications that collect and share information on natural risks and emergencies. For example the ESRI's Disaster Response Program (http://www.esri.com/services/disasterresponse/earthquakes), a platform that is a supporting for organizations that are responding to earthquake and tsunami disasters with software, data, imagery, project services, and maps. An interactive earthquake map that show the earthquake locations, shaking intensity, and population as well as social media updates regarding earthquakes that have occurred around the world. The web interface for sharing and distribution of real-time seismic data recorded by the National Seismic Network (INGV) in Italy is ISIDE - Italian Seismic Instrumental and parametric data-base (http://iside.rm.ingv.it/), where it is possible to search and download the data, also in geographic formats. In recent years different WebGIS applications have been developed by the LABGIS of INGV-Irpinia (Grottaminarda-AV) using ArcGIS Online and the real time seismic data from ISIDE. An example is GEOSIS, a WebGIS application 
showing recent and real time seismicity, extracted by ISIDE, with other useful geographic data derived from other INGV databases and studies, such as historical seismicity, seismic hazard, seismic classification, the last thirty years seismicity (Pignone et al. 2012). The evolution of ArcGIS Online and the development and recent publication of the INGV- Centro Nazionale Terremoti (CNT, National Earthquake Centre) Webservices (http://cnt.rm.ingv.it) allowed the design and implementation of a new application software for the management of the seismic data and those of the monitoring networks in real time (called XPY) constituted by a set of scripts and procedures. The architecture of XPY system is formed by two servers located in the data center of Grottaminarda on which run a series of python scripts for finding, processing and publishing the real time seismic data and the real time monitoring networks data.

The XPY system runs in the background and performs the following operations (Figure 2):

- interrogation of Web-services of the $\mathrm{Na}$ tional Earthquake Center (http://webservices.rm.ingv.it/fdsnws/e vent/1/). XPY requires the list of earthquakes located by the National Seismic Network in the last " $X$ " days;

- the event list obtained by Web-services is processed and some CSV (commaseparated values) files are generated as needed; for example the last earthquake, the last 24 hours earthquakes or those of last 30 days;

- the generated CSV files are processed to classify events based on specific attributes such as: magnitude intervals, time intervals, geographic areas (this allows the creation of different GIS layers);

- for the information relating to the positioning and characteristics of the INGV permanent monitoring stations, the query is performed at SEISFACE (the Web interface for managing and locating information of INGV SEISNET database) and contains information in real time about the monitoring networks;

- synchronization of CSV files produced by queries with the sharing webserver and online publication.

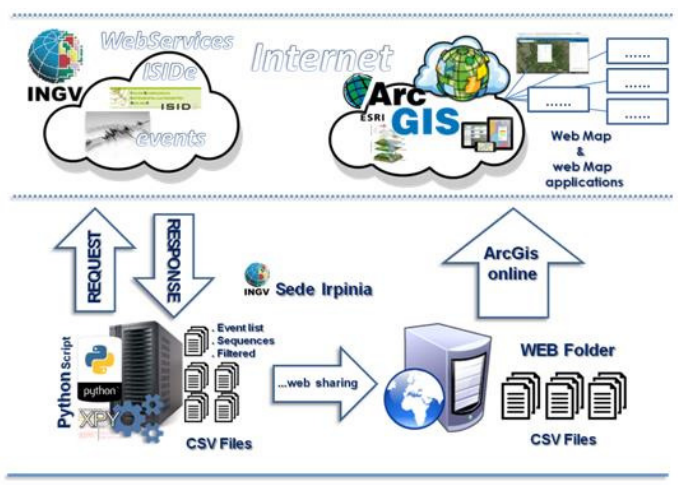

Figure 2: The operation of the XPY system and the integration of data in ArcGIS Online.

All the parameters that determine the production of the CSV files are managed by the XPY system through a configuration file that determines the scripts settings and can be modified at run-time without the stop and reboot of the system. It is possible to edit the configuration file by changing the parameters or by adding new processing requests.

The CSV data of real-time seismicity, made and shared on the web through the XPY system, can be easily integrated within ArcGIS 
Online as a Web CSV layer with the possibility of defining an update time interval. These CSV files can also be downloaded and used with desktop GIS software for the production of thematic maps. During the seismic emergency in central Italy, the data source for the thematic maps published on the web portal of the INGV (www.ingv.it) and on the INGVterremoti communication platform

(http://ingvterremoti.wordpress.com) have been these CSV files. The map (Figure 3) has been realized using several layers, classified and displayed according to the magnitude classes (symbols size) and the time (colors) to follow the temporal evolution of the cen- tral Italy seismic activity. The chosen symbology has been conceived to provide an immediate impact of the ongoing activity, and is analogous to the symbology adopted in the CNT web pages (http://cnt.rm.ingv.it) and in the INGVterremoti App on IOS and Android.

\section{WEB APPLICATIONS FOR MANAGING AND SHARING GEOGRAPHIC DATA DURING THE SEISMIC EMERGENCY}

Due to the development of the XPY system and to new functionalities available in the recent versions of ArcGIS Online it was possible to improve the integration and sharing

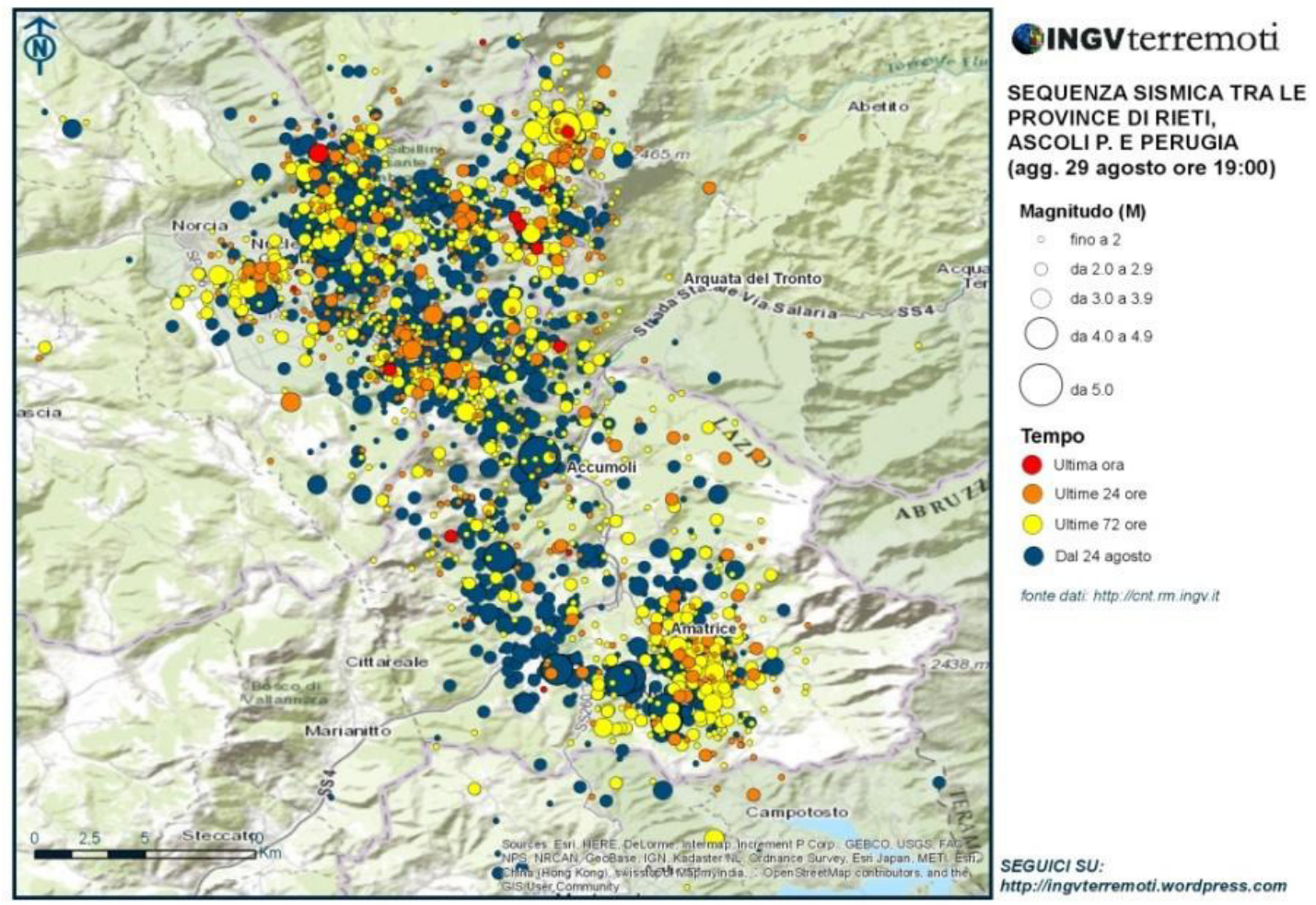

Figure 3: Thematic map of spatio-temporal distribution of the seismic sequence. 
of geographic data for the emergency management activities through the development of a work platform in ArcGIS Online. This platform was tested during the earthquake simulation organized by INGV in November 2015 and used during the seismic emergency in August 2016 (magnitude 6.0 earthquake on August 24th between the provinces of Rieti and Ascoli Piceno). The work platform is constituted by several Web-maps and Web applications for the management and updating of the seismic data and the monitoring networks in real time and their integration with the principal INGV seismological and seismotectonic databases and those of other Institutes. In the maps, it is also possible to directly manage and share information and data from the activities of the INGV Emergency Groups (https://ingvterremoti.wordpress.com/ilmonitoraggio-sismico/attivita-inemergenza/), for example, the position and characteristics of temporary seismic and accelerometric stations installed by SISMIKO and EMERSITO teams but also the geological observations from surveys of geologists of EMERGEO. Starting from these Web-maps, the Web applications have been developed using the ArcGIS Online template or the Application Builder for ArcGIS; the Web applications have been shared within the INGV Crisis Unit (the team that coordinates all the INGV emergency activities) and Emergency Groups in order to coordinate the activities on epicentral area.

\section{Data from the Emergency Groups}

During the early days of the seismic sequence in central Italy, to simplify the interaction and sharing of information from the different INGV Emergency Groups operating in epicentral area, a data-sharing system was used through a Google spreadsheet (Google DOCS) platform which is used normally by INGV for the mail service, storage, etc. Each group was responsible for implementation and updating the table (a Google spreadsheet) created specifically for their activities. The table shared among all the participants of the emergency activities could be populated or changed simultaneously by one or more users in real time. The table generated a CSV file that, loaded in the Web-map of ArcGIS Online as a CSV Layer, allowed the visualization of geographical information updated in real time (Figure 4).

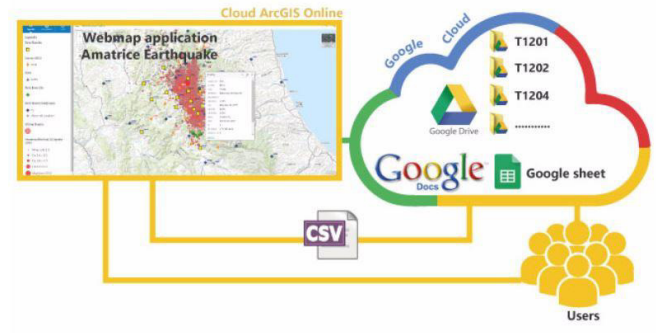

Figure 4: The integration of Google documents within ArcGIS online Web-maps.

For example, for the SISMIKO group, the information provided on Google document table is relative to sites hosting the installed temporary seismic stations and the characteristics of instrumentation. In the ArcGIS Online Web-map, the SISMIKO layer shows 
the temporary stations displayed in different colors indicating the teams from Rome, Grottaminarda, Ancona and Pisa, participating to the installation of the stations. This has allowed for following day-to-day progress in the implementation of the network of each team. It is possible to query the map by clicking on each station to see the pop-up of the detailed information relating to the individual station. The pop-up allows for displaying of the name, the location, the coordinates, the type of power, the type of connectivity for each station and also for incorporating multimedia elements collected during installation phase (Figure 5). In this way, all the SISMIKO members share the information and documents in real time; proving is useful for planning new installations. Similarly, other CSV layers have been generated for other networks installed by Emergency Groups like EMERSITO and for geological field observations detected by the geologists of EMERGEO Group.

\section{$\underline{\text { Seismicity and other data in real time }}$}

The real time seismicity has been organized, in the ArcGIS Online Web-maps, in layers in which the earthquakes localized by the National Seismic Network are represented by a different color for each temporal interval and classified in five classes of magnitude value.

This representation type is consistent with that used in the maps of the National Earthquake Center website (http://cnt.rm.ingv.it), in the maps of the INGVterremoti blog and in the INGVTerremoti App for iOS and Android:

- earthquakes in the last hour (red)

- earthquakes in the last 24 hours (orange)

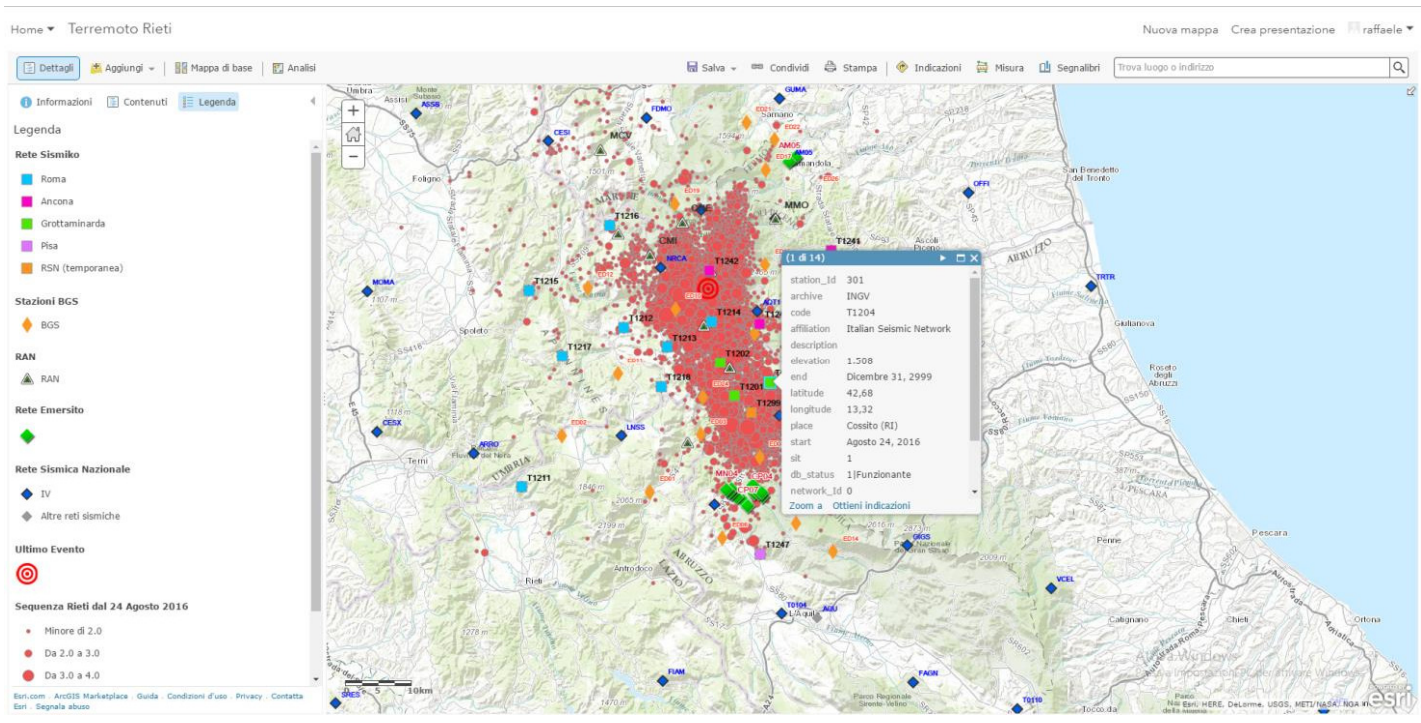

Figure 5: The ArcGIS Online Web Map for management of SISMIKO activities with the attributes of the temporary stations layer. 
- earthquakes in the last 3 days (yellow)

- earthquakes from January $1^{\text {st }} 2016$ (blue)

For the INGV permanent monitoring networks, the following layers have been produced with the detailed information for each station and its operation level:

- National Seismic Network Stations (RSN)

- INGV Accelerometric Network Stations

- National Integrated GPS Network Stations (RING)

Database and Catalogues from INGV and other Institutes

Some datasets have been extracted, in different export formats (text and geographic format), from the INGV and other Institutes catalogues and databases and, with some operations, have been made compatible as layers for the ArcGIS Online Web-maps. For each layer, appropriate classification and thematization have been created and popups have been configured to display some of the attributes included in the database:

- instrumental seismicity 2006-2016, extracted from the ISIDE database (http://iside.rm.igv.it) with events of magnitude $\geq 2.5$ (4 different classes of magnitude);

- instrumental seismicity 1985-2005, extracted from the ISIDE database with magnitude $\geq 3.0$ seismic events ( 4 different classes of magnitude);

- strong earthquakes of the past extracted from CPTI15, the 2015 version of the
Parametric Catalogue of Italian Earthquakes

(http://emidius.mi.ingv.it/CPTI15DBMI15/) with events of estimated magnitude (Mwdef) $\geq 5.0$ (5 different classes of magnitude) ;

- national seismic hazard map (GdL MPS, 2004; Ordinanza PCM, April 28, 2006, n. 3519 , All. $1 \mathrm{~b}$ ); it provides the $10 \%$ probability of exceedance in 50 years of the horizontal acceleration at rock sites (i.e., Vs30 $>800 \mathrm{~m} / \mathrm{s}$; cat. A, 3.2.1 of the D.M. 14.09.2005,

http://zonesismiche.mi.ingv.it);

- database of individual seismogenic $\begin{array}{lll}\text { sources, } & \text { DISS } & 3.2 .0\end{array}$ (http://diss.rm.ingv.it/diss/), divided into individual seismogenic sources, composite seismogenic sources, debated seismogenic sources.

In some maps, several map-services of other institutions dataset have been uploaded in WMS format (Open Geospatial Consortium standard): for example, the Lithological Map of Italy and the database of faults ITHACA from ISPRA, the maps of Copernicus Emergency Management Service for the Central Italy Earthquake. The ArcGIS Online layers of data from emergency teams and real time seismicity are shared exclusively with users involved in emergency. This choice is justified by two reasons: the first is that many of the collected data are still provisional and, therefore, cannot be shared outside, the second is that sharing of ArcGIS Online layers of real time seismicity during an emergency, there are no certainties on ESRI of cloud platform performance for a high number of viewing requests. 


\section{The development of WebGIS applications}

Once the data within the work platform in ArcGIS Online has been organized and loaded in the Web-maps it has been possible to transform maps into WebGIS applications with basic and customized functionalities. ArcGIS Online provides different Web application templates with the possibility to customize them according to the type of features and preferred layout. Another possibility is to use the Web Application Builder for ArcGIS that provides a foundation for building Web applications in ArcGIS Online without writing a single line of code. With Web AppBuilder, it is possible to create a custom HTML / javascript Web application, to configure the look-and-feel of the app by picking a theme that includes a collection of panels, styles, layouts, and pre-configured widgets, add others widgets and functionality. The Web applications run on any device including tablets and smartphones. Several custom Web applications have been developed for the activities management and the data sharing of the INGV Emergency Groups. For example, for EMERGEO a WebGIS has been developed with a layer of earthquake observations (classified in coseismic rupture, co-seismic fracture, coseismic sliding, no co-seismic effect) and a Web interface with these functionalities: legend, layer list, add data, print, basemaps, measure, bookmarks, info (Figure 6).

Among the features included within web interfaces, ADD DATA allows to add other shared geographic ArcGIS Online layers (they can be searched by keywords), or to add layers from outside in different formats (ESRI ArcGIS Server Map Service, WMS OGC Map Service, KML, GeoRSS, CSV). This feature allows, therefore, to integrate any geographic data of users with scenarios realized through the emergency data.

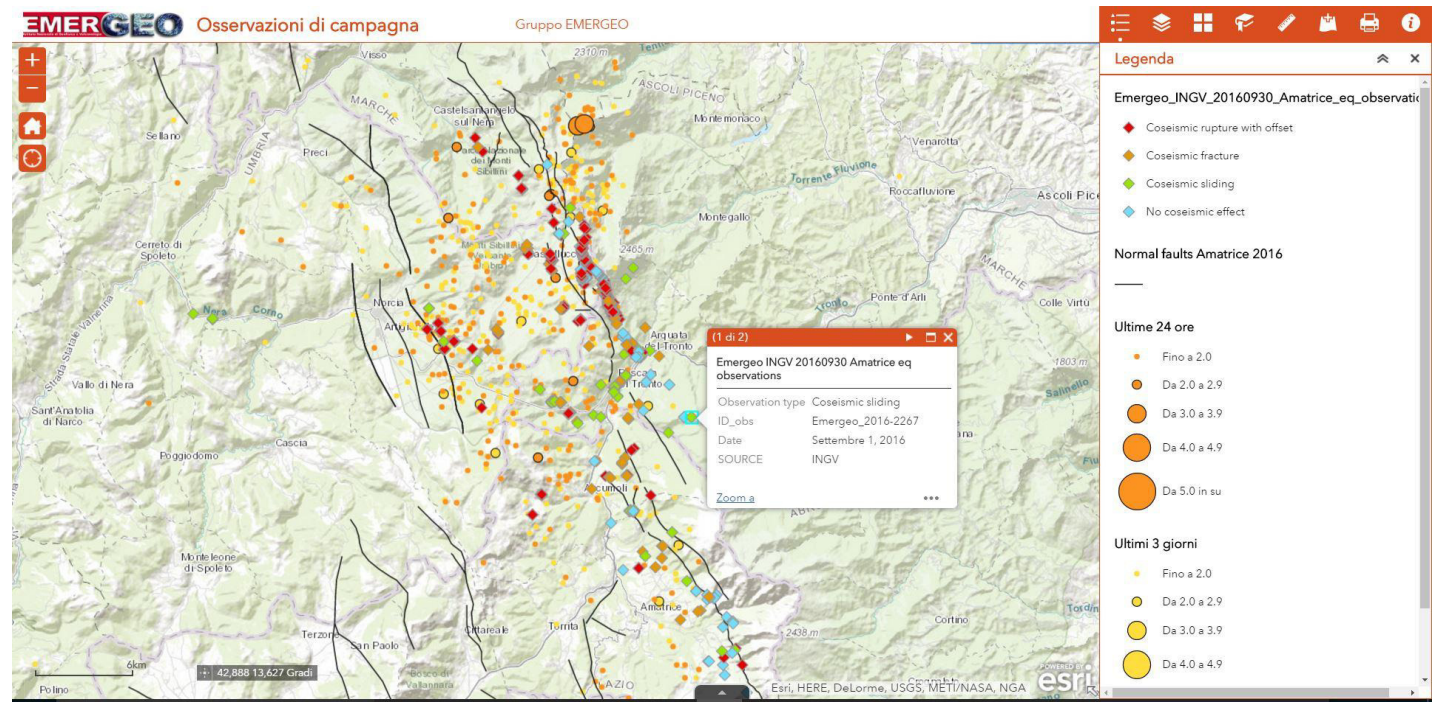

Figure 6: The interface of EMERGEO WebGIS_with functionalities avaible on top-right. 
III. CONCLUSIONS AND FUTURE DEVELOPMENTS

The realization of this Cloud-GIS platform has enabled the management and updating of the seismic data of the Central Italy sequence in real time and their integration with the main INGV seismological and seismotectonic databases. Moreover the platform has allowed for better management of sharing of geographic data produced by different INGV emergency groups, such as the location and characteristics of seismic and accelerometric temporary stations installed by SISMIKO and EMERSITO teams and the geological observations from the EMERGEO Group. Due to Web applications it has been possible to create scenarios to manage the emergency activities by integrating different types of geographic data from different sources. The opportunity to manage realtime data and integrate with different databases made dynamic scenarios providing support tools for assessments and decisions of the INGV Crisis Unit for the activities of emergency management in Central Italy.

Platform development is continuous and aims at various targets: displacement of XPY system entirely in the cloud; an improvement in the display performance of geographic data; creating customized functionality in web applications (for example some functions for proximity and spatial analysis); mobile applications for data collection and the direct input in google documents; sharing to all of the real-time seismic data using
OGC WMS services, and ArcGIS Online layers.

\section{REFERENCES}

Pignone M., Moschillo R., (2011). GEOSIS WEB, Atti della 15a Conferenza Nazionale ASITA, Federazione italiana delle Associazioni Scientifiche per le Informazioni Territoriali e Ambientali, Reggia di Colorno, ISBN 978-88-903132-6-4, http://www.earthprints.org/handle/2122/7489.

Pignone M. e Moschillo R. (2012). GEOSIS: dall'earthquake report al WebGIS, Quaderni di Geofisica INGV n. 94, ISSN 15902595, http://www.earthprints.org/handle/2122/7077, 2011.

Pignone M., Moschillo R., Cogliano R., (2012). GEOSIS, An interactive Web-map of earthquakes in Italy, Rendiconti online Soc. Geol. It., Vol. 19/2012, pp. 20-23, ISSN 2035-8008.

Pignone M., Moschillo R., Cogliano R., (2012). A WebGIS application for visualization and dissemination of italian seismicity, Proceedings $7^{\circ}$ European Congress on Regional Geoscientific Cartography and Informations Systems, Bologna 2012, Volume II, pp. 644-645, http://www.earthprints.org/handle/2122/8032. 